\title{
O impacto do investimento em pesquisa, desenvolvimento e inovação na geração de valor de empresas farmacêuticas
}

\section{The impact of investment in research, development and innovation on value generation of pharmaceutical companies}

\author{
BRUNO BARBOSA BRONZERI (D) \\ FABIO GALLO GARCIA \\ ELMO TAMBOSI FILHO D
}

\section{RESUMO}

O presente trabalho realiza uma análise da indústria farmacêutica mundial, tendo em vista o crescimento contínuo desse segmento e o volume de recursos aplicados em Pesquisa, Desenvolvimento \& Inovação (PD\&I), a fim de entender como esse investimento impacta no valor da empresa, considerando produtos inovadores e projetos de produtos no pipeline. Foi desenvolvida uma análise quantitativa multivariável através do modelo de regressão logística com dados em painel de nove empresas farmacêuticas mundiais entre os anos de 2009 e 2018 . Verificando-se que as empresas mais inovadoras e mais eficientes em PD\&I adicionam mais valor. Foi possível, ainda, constatar a importância da redução do conflito de agência considerando que o possível atraso no lançamento de novos produtos por parte dos executivos pode estar impactando negativamente na geração de valor da empresa para as empresas do setor farmacêutico aqui estudadas.

Palavras-chave: Pesquisa, Desenvolvimento \& Inovação. Geração de Valor. Indústrias Farmacêuticas. 


\section{Abstract}

The present work analyzes the pharmaceutical industry worldwide, considering the continuous growth of this segment and the volume of resources invested in Research, Development \& Innovation (RD\&I), in order to understand how this investment impacts the company's value, considering products innovative products and pipeline product designs. A multivariate quantitative analysis was developed using a logistic regression model with panel data from nine pharmaceutical companies worldwide between 2009 and 2018. It was verified that the most innovative and most efficient companies in RD\&I add more value. It was also possible to verify the importance of reducing agency conflict, considering that the possible delay in the launch of new products by executives may be negatively impacting the company's value creation for the companies in the pharmaceutical sector studied here.

Keywords: Research, Development and Innovation. Value generation. Pharmaceutical Industries.

\section{InVESTIMENTO EM PD\&I E CONFLITO DE AGÊNCIA}

Impulsionados pela gestão de resultado de curto prazo pode-se admitir que os executivos tendem a postergar investimentos de longo prazo mesmo impactando negativamente na adição de valor da empresa. Salter (2012), baseado em pesquisa realizada pela US Chief Financial Officers identificou que $80 \%$ dos executivos estão dispostos a cortar despesas não relacionadas à operação e 55\% postergariam investimentos em novos projetos. Esse comportamento, contrário à expectativa dos acionistas é considerado na administração financeira dentro do espectro da teoria de agência. Quando há um desencontro das ações e interesses entre os executivos que administram a empresa e os acionistas é gerado um conflito de agência.

Uns dos investimentos suscetíveis a esse comportamento são os investimentos em Pesquisa, Desenvolvimento e Investimentos (PD\&I). Segundo o Guia 2019 Interfarma (2019), o setor farmacêutico possui o maior grau de investimentos quando comparado aos demais setores, ficando $15 \%$ acima do segundo setor com maior volume de investimentos. No entanto, "aumento nos gastos com PD\&I em produtos farmacêuticos de grande capitalização são 
analisados de forma negativa pelos investidores de curto prazo" (FEYZRAKHMANOVA; GURDGIEV, 2016).

Aproximadamente $33,8 \%$ das razões para cancelamento dos projetos de PD\&I estão relacionadas a questões econômicas, como taxa de retorno insuficiente ou mercado comercial não atrativo (DIMASI 2001)

A questão do conflito de agência e a relevância dos investimentos em PD\&I no setor farmacêutico, atrelado ao risco de postergação de investimentos de longo prazo por parte dos executivos, tem-se a seguinte questão de pesquisa:

Os investimentos em PD\&I no setor farmacêutico de capital aberto são ajustados pelo retardo na conversão de novos produtos patenteados, impactando negativamente na geração de valor da empresa?

Assim, tem-se que o objetivo do presente estudo é verificar se há impacto negativo dos ajustes de investimento em PD\&I na geração de valor das empresas mundiais do setor farmacêutico de capital aberto, no período entre 2009 e 2018.

Tendo como base o objetivo proposto será buscado a análise das seguintes situações:

a) Empresas mais inovadoras, que possuem maior volume de vendas de produtos inovadores relativamente ao seu faturamento total, geram valor;

b) mpresas que melhor gerenciam os produtos estabelecidos geram valor;

c) Empresas com maior volume de investimentos em pesquisa, desenvolvimento e inovação geram valor;

d) Empresas mais eficientes em PD\&I, que possuem menor relação de investimento em PD\&I por projeto em pipeline ou menor investimento em PD\&I relativo ao faturamento total, geram valor.

A relevância do presente estudo é objetiva quando se busca verificar se há um de impacto negativo na geração de valor da empresa ocasionado dos investimentos em pesquisa, desenvolvimento e inovação é relevante para incentivar os executivos a uma gestão com visão de longo prazo canalizando os investimentos para projetos com maiores retornos corroborando para os estudos de Teoria da Agência e Geração de Valor. 
Espera-se que a presente pesquisa possa trazer uma reflexão por parte dos executivos no que tange a tomada de decisão relacionada à postergação de investimentos em PD\&I considerando a geração de valor da companhia associada à expectativa dos acionistas.

\section{GERAÇÃo DE VALOR NO MERCADO FARMACÊUTICO}

De acordo com o EvaluatePharma World Preview 2019 (PHARMA, 2019) o mercado farmacêutico mundial atingiu faturamento, em 2018, de US $\$ 827$ bilhões demonstrando um crescimento médio acumulado de 2,3\% desde 2010 ficando abaixo da expectativa, para 2018, de US\$ 895 bilhões projetada pela EvaluatePharma em 2013 (PHARMA, 2013).

Apesar do desempenho abaixo do esperado, a expectativa de crescimento médio acumulado entre 2018 e 2024 é de 6,1\% ao ano devendo atingir as vendas de US\$ 1.181 bilhões. O crescimento está atribuído basicamente às novas terapias sendo que $30 \%$ são referentes aos medicamentos órfãos utilizados em doenças raras e que necessitam de ajuda governamental por não possuírem potencial mercadológico (PHARMA 2017). Segundo EvaluatePharma na publicação World Preview 2019 Outlook to 2024 (PHARMA, 2019), o crescimento é decorrente das "extensões de linha de imuno-oncologia" e do "surgimento de novas tecnologias, como a terapia celular e genética que marcam um ponto de inflexão na evolução da indústria farmacêutica" (PHARMA 2019).

\subsection{Pesquisa, desenvolvimento \& inovação no setor farma- cêutico}

O processo de desenvolvimento de um novo medicamento é longo e pode durar aproximadamente entre 10 e 15 anos para ser concluído (Pharma, 2012). O desenvolvimento de um novo medicamento é complexo e a efetividade do processo de desenvolvimento é medida pela taxa de sucesso, que é um indicador que mede a probabilidade acumulada de sucesso de um projeto desde a fase inicial até a fase de aprovação pelo órgão regulador (Dimasi, Feldman, Seckler e Wilson (2010).

Estima-se que a taxa de sucesso de desenvolvimento de um novo medicamento é de aproximadamente 13,8\% (Wong, Siah, Lo, 
2019). Dimasi, Feldman, Seckler e Wilson (2010) afirmam que a taxa de sucesso pode variar dependendo do tipo de molécula em desenvolvimento (ex, macromolécula ou pequena molécula) ou do tipo de classe terapêutica (ex, sistema nervoso central, cardiovascular, musculoesquelética, et.).

Dimasi (2001) demonstra que $57,2 \%$ das razões para a taxa de insucesso no desenvolvimento de um novo medicamento estão relacionadas às questões técnicas, como eficácia e segurança, porém ressalta que $33,8 \%$ das razões estão relacionadas às questões econômicas, como ambiente comercial limitado e retorno sobre investimento insuficiente.

Como consequência da taxa de sucesso, o custo de desenvolvimento para uma molécula se tornar comercializável pode chegar até US\$ 2,8 bilhões incluindo os custos dos projetos que foram cancelados ao longo das fases e os custos necessários após a aprovação pelo órgão regulador (Dimasi, Grabowski, Hansen, 2016).

De acordo com o EvaluatePharma World Preview 2019 (PHARMA, 2019) o volume de investimentos em PD\&I no mercado farmacêutico mundial cresceu em média 4,2\% ao ano entre o período de 2010 e 2018 atingindo US\$ 179,0 bilhões no ano de 2018. Contra o ano anterior, o crescimento foi de $6,5 \%$, o que representa a segunda maior taxa de crescimento nos últimos oito anos, segundo o Guia Interfarma (2019), e configura-se como o setor com o maior setor em investimentos em PD\&I. No entanto, o crescimento médio esperado para os próximos cinco anos é de 3,0\%. O que demonstra a prioridade em uma estrutura de PD\&I mais eficiente.

\subsubsection{A busca por produtividade em PD\&I}

A intensidade na capacidade de investimento pode ser justificada pela observação de sua direta correlação com o desempenho operacional das empresas farmacêuticas concluindo-se que "quanto maior a intensidade de entrada de Pesquisa e Desenvolvimento das empresas farmacêuticas, maior o desempenho operacional" (CHANG, XUEMENG, ZHUOJUN, 2018, p.525). Apesar do investimento em PD\&I agregar vantagem competitiva, pode não se demonstrar benéfico no curto prazo (SANTOS et al, 2015). 
Ramos e Zilber (2015) demonstram uma correlação direta e positiva "entre séries temporais de investimentos realizados em PD\&I e de receitas de vendas, observando-se as defasagens temporais entre os eventos registrados nas demonstrações financeiras das empresas".

Apesar dos estudos comprovarem a relação direta entre investimento de lucratividade, mesmo que obedecendo a defasagem do tempo, os aumentos nos gastos com PD\&I em empresas farmacêuticas de grande capitalização são vistos negativamente pelos investidores no curto prazo (FEYZRAKHMANOVA;; GURDGIEV, 2016).

Se por um lado houve melhora na produtividade de PD\&I nos últimos anos através da redução do custo de sequenciamento de um DNA, menos horas-homens para determinar a estrutura de proteína e redução no custo de testar moléculas, por outro lado os gastos com PD\&I aumentaram proporcionalmente muito superior aos ganhos de produtividade (SCANNELL et al., 2011), levando à uma redução do retorno do investimento esperado. O retorno de projetos em PD\&I reduziu de 10,9\% para 1,9\% entre 2010 e 2018 decorrente do aumento com os custos com pesquisa e desenvolvimento de medicamentos biofarmaceuticos. (DELOITTE, 2018).

Apesar dos gastos em PD\&I terem aumentado, o resultante do processo de desenvolvimento de novas moléculas tem sido desafiador. Para Henry, Grabowski e Wang (2006), que analisaram com introduções de moléculas, entre o período de 1982 e 2003, observaram que apesar das reduções de novas moléculas nos últimos anos, houve um aumento considerável nas moléculas de alta qualidade, em especial para tratamento de câncer. Pammolli, Magazzini e Riccaboni, (2011) avaliaram mais de 28 mil projetos durante o período de 1990 a 2010 e observaram maior concentração dos investimentos de PD\&I em áreas mais complexas como necessidades terapêuticas não atendidas e mecanismos biológicos não atendidos, os quais possuem maior risco de falha de desenvolvimento.

Como possível consequência dessas mudanças, Dimasi, Feldman, Seckler e Wilson (2010) afirmam que a taxa de sucesso tem sido reduzida em relação aos estudos anteriores. Isso pode ser concluído como uma necessidade de as empresas manterem mais projetos em pipeline para que possam manter o nível de faturamento atrelado a produto inovadores. 
Conforme tabela 3, a quantidade de novas moléculas com aprovação no FDA atingiu 27 em 2016, resultando em uma redução de $50 \%$ sobre o ano anterior, o que se configura como o terceiro pior ano desde 2006 e "serve para destacar a escassez de novos medicamentos" (PHARMA, 2017, p. 4). Como resultado, houve um aumento significativo em 2016 no custo de desenvolvimento por novas molécula aprovadas por ano em aproximadamente $100 \%$ contra os últimos anos, atingindo US\$ 5,9 bilhões em 2016.

Em 2018, a quantidade de moléculas aprovadas atingiu 62, um crescimento de $130 \%$ sobre 2016 , porém com um custo per capta de US\$2,9 bilhões, que representa uma redução de $50 \%$ sobre 2016. Pammolli (2020) observou 50 mil projetos no período entre 1990 e 2017 e identificou melhora na produtividade em PD\&I das bio-farmaceuticas, aumento na quantidade de projetos de terapia avançada e que os projetos bem-sucedidos recentemente baseiam-se em novos mecanismos de ação e visam novas indicações.

Tabela 3: Novas moléculas aprovadas por ano

\begin{tabular}{l|c|c|c|c|c|c|c|c}
\hline Ano & 2011 & 2012 & 2013 & 2014 & 2015 & 2016 & 2017 & 2018 \\
\hline Número de novas moléculas & 35 & 44 & 35 & 51 & 56 & 27 & 55 & 62 \\
\hline $\begin{array}{l}\text { Gastos por novas moléculas } \\
\text { (US\$ bilhões) }\end{array}$ & 3,9 & 3,1 & 4 & 2,8 & 2,7 & 5,9 & 3,1 & 2,9 \\
\hline
\end{tabular}

Fonte: Adaptação do autor, a partir do EvaluatePharma ${ }^{\circledR} 2019$

Em contrapartida, houve manutenção do Faturamento após cinco anos de lançamento por novas moléculas acima do patamar de US\$ 400 milhões desde 2003, atingindo US\$ 522 milhões em 2016 (PHARMA, 2017). Essa performance reforça a tendência das empresas de serem mais produtivas em PD\&I como foco em "indicações menores com menor carga de custos de desenvolvimento clínicos" (PHARMA, 2019)

Nesse cenário, as grandes empresas multinacionais farmacêuticas têm tomado ações para aumentar a produtividade em Pesquisa e Desenvolvimento. A Pfizer anunciou redução de 30\% no orçamento com PD\&I entre 2010 e 2012 e, como contrapartida "expandiu sua presença em Cambridge, Massachusetts, especificamente para ter um melhor acesso colaborativo às grandes instituições de pesquisa da área e para adotar uma postura de inovação aberta" (INDUS- 
TRIAL, 2011), aderiu ao Structural Genomics Consortium que apoia a descoberta de novos medicamentos por meio de pesquisa em acesso aberto através de uma parceria Público-Privada e que consta com a participação da GlaxoSmithKline, da Novartis, e da Eli Lilly (INDUSTRIAL, 2011). Outro modelo de desenvolvimento em colaboração é o "One Mind for Research", um esforço para construir um repositório global de dados relevantes, imagens e informações de pacientes para pesquisas colaborativas em neurociência e desordens cerebrais" (INDUSTRIAL, 2011, p. 47).

\section{Metodologia}

\subsection{Variáveis de análise}

A análise foi realizada em duas etapas, sendo a primeira relacionada ao levantamento de dados relacionados as variáveis independentes seguindo a seguinte hierarquia metodológica:

a) Identificar a venda de produto inovadores e o investimento em Pesquisa \& Desenvolvimento por projeto em pipeline.

b) Identificar as empresas e o período que adicionaram valor;

c) Correlacionar as variáveis de investimentos em PD\&I, evolução das vendas de produtos patenteados, evolução das vendas de produtos estabelecidos e quantidade de produtos em pipeline.

A identificação da venda de produtos inovadores permitirá a compreensão do grau de inovação da empresa possibilitando o entendimento do diferencial competitivo. O levantamento do investimento em Pesquisa \& Desenvolvimento por projeto poderá conscientizar sobre a produtividade relativa ao mercado do processo de desenvolvimento de novos produtos conduzir os gestores para uma reflexão comparativa entre a intensidade de investimento em P\&DI versus a velocidade de conversão de projetos em produtos comercializáveis. Além disso, a identificação do período de adição de valor permitirá observar a eficiência do processo de desenvolvimento de produtos culminando em adição de valor ao acionista.

Dessa forma, foram especificados os seguintes grupos de variáveis independentes descritos na tabela 1: 


\section{Tabela 1 - Variáveis Independentes}

\begin{tabular}{|c|c|c|c|c|}
\hline ID & Variável & Descrição & Levantamento & Unidade medida \\
\hline $\mathrm{X} 1$ & PD\&I \$ & Despesas com pesquisa \& desenvolvimento & Conforme relatório anual & US\$ milhões \\
\hline $\mathrm{X} 2$ & $\%$ PD\&I s/ FAT & $\begin{array}{l}\text { Despesas com pesquisa \& desenvolvimento } \\
\text { ajustado ao tamanho da empresa }\end{array}$ & $\begin{array}{l}\text { Despesas com PD\&I / } \\
\text { Faturamento Total }\end{array}$ & $\%$ \\
\hline $\mathrm{X} 3$ & $\%$ FAT_INOV s/ FT & $\begin{array}{l}\text { Faturamento de produtos inovadores, ou } \\
\text { patenteados ajustado ao tamanho da empresa }\end{array}$ & $\begin{array}{l}\text { Faturamento Produtos Inovadores } \\
\text { / Faturamento Total }\end{array}$ & $\%$ \\
\hline $\mathrm{X} 4$ & FAT_ESTAB & Faturamento Produtos Estabelecidos & $\begin{array}{l}\text { Faturamento total - Faturamento } \\
\text { Produtos Inovadores }\end{array}$ & US\$ milhões \\
\hline $\mathrm{X} 5$ & Q_PROJ & Projetos publicados no pipeline; & $\begin{array}{l}\text { Contagem conforme publicado } \\
\text { relatório anual }\end{array}$ & Quantidade \\
\hline $\mathrm{X} 6$ & R\$PD\&I_PROJ. & $\begin{array}{l}\text { Investimento em pesquisa \& desenvolvimento } \\
\text { por projeto }\end{array}$ & \$PDI / \#PDI & $\begin{array}{l}\text { US\$ milhões / } \\
\text { Projeto }\end{array}$ \\
\hline
\end{tabular}

Fonte: Elaboração própria.

Como variável dependente para representar a geração de valor das empresas analisadas será considerado o EVA spread e assume-se a premissa de que quando EVA spread for positivo a empresa adicionou valor e, quando EVA spread for negativo a empresa destruiu valor.

\section{Amostra}

O levantamento das variáveis conforme a tabela 1 foi realizado através das Demonstrações Financeiras publicadas entre 2009 e 2018 pelas maiores indústrias farmacêuticas do mundo e estão demonstrados por empresa no anexo A. Vale destacar, que para determinação da quantidade de projetos em pipeline serão contabilizados todos os projetos demonstrados no relatório anual das respectivas empresas. As premissas para identificação do faturamento e informações gerais das empresas da amostra pesquisada estão organizadas apêndice A.

O levantamento do Valor Econômico Adicionado, ou seja, o Economic Value Added (EVA), os dados das empresas de analisadas foram obtidos por consulta a plataforma Bloomberg ${ }^{1}$ e estão representados por empresa conforme anexo A. As empresas farmacêuticas do mercado brasileiro não foram consideradas nesse estudo por 1 
serem em maioria de capital fechado e que por iniciativa própria divulgam informações restritivas.

Amostragem da pesquisa será baseada no levantamento das indústrias farmacêuticas com maior volume de PD\&I representando $47,4 \%$ do investimento mundial, conforme tabela 2 , cruzando com o ranking das empresas com maior faturamento, cuja representatividade é de $50 \%$ do faturamento mundial, conforme tabela 3, compondo as 13 maiores indústrias do mercado mundial farmacêutico. Vale destacar que o mercado é bem competitivo e as demais empresas possuem baixa participação de mercado tanto em investimentos em PD\&I quanto em vendas com participação de mercado (MKS) abaixo de $1,8 \%$ e $2,3 \%$ respectivamente, o que torna irrelevante a adição de outras empresas na amostragem. Para essa análise não será considerado os dados do EvaluatedPharma 2019 por ter sido publicado o ranking somente com as dez maiores.

Tabela 2 - Gastos com PDEI empresas farmacêuticas 2017 (US\$ Bilhões)

\begin{tabular}{l|cc}
\hline \multirow{1}{*}{ Ranking } & \multicolumn{2}{c}{2017} \\
\cline { 2 - 3 } PD\&I & US\$ Bi & mks \\
\hline Roche & 9,2 & $5,6 \%$ \\
Johnson \& Johnson & 8,4 & $5,1 \%$ \\
Novartis & 7,8 & $4,7 \%$ \\
Merck \& Co & 7,6 & $4,6 \%$ \\
Pfizer & 7,6 & $4,6 \%$ \\
Sanofi & 6,2 & $3,8 \%$ \\
AstraZeneca & 5,4 & $3,3 \%$ \\
GlaxoSmithKline & 5,0 & $3,0 \%$ \\
Eli Lilly & 5,0 & $3,0 \%$ \\
AbbVie & 4,8 & $2,9 \%$ \\
Bristol-Myers Squibb & 4,8 & $2,9 \%$ \\
Amgen & 3,5 & $2,1 \%$ \\
Celgene & 3,0 & $1,8 \%$ \\
\hline Total Top 13 & 78,3 & $47,4 \%$ \\
\hline Outros & 86,8 & $52,6 \%$ \\
\hline Total & 165,1 & $100,0 \%$ \\
\hline Fonte: Adaptac̃
\end{tabular}

Fonte: Adaptação do autor, EvaluatePharma 2018. 
Tabela 3 - Vendas mudiais de medicamentos 2017 (US\$ Bilhões)

\begin{tabular}{l|cc}
\hline \multirow{1}{*}{\multicolumn{1}{c}{ Ranking }} & \multicolumn{2}{c}{2017} \\
\cline { 2 - 3 } Faturamento & US\$ Bi & mks \\
\hline Pfizer & 45,4 & $5,8 \%$ \\
Novartis & 41,9 & $5,3 \%$ \\
Roche & 41,7 & $5,3 \%$ \\
Merck \& Co & 35,4 & $4,5 \%$ \\
Johnson \& Johnson & 34,4 & $4,4 \%$ \\
Sanofi & 34,1 & $4,3 \%$ \\
GlaxoSmithKline & 28,7 & $3,6 \%$ \\
AbbVie & 27,7 & $3,5 \%$ \\
Gilead Sciences & 25,7 & $3,3 \%$ \\
Amgen & 21,8 & $2,8 \%$ \\
AstraZeneca & 19,8 & $2,5 \%$ \\
Bristol-Myers Squibb & 19,3 & $2,4 \%$ \\
Eli Lilly & 18,5 & $2,3 \%$ \\
\hline Total Top 13 & 394,4 & $50,0 \%$ \\
\hline Outros & 394,4 & $50,0 \%$ \\
\hline Total & 788,8 & $100,0 \%$ \\
\hline Fonte: Adaptação do autor, EvaluatePharma 2018.
\end{tabular}

Dessa amostragem foram excluídas as empresas Johnson \& Johnson, que possui relevante representação no mercado de consumo, e as empresas AbbVie, Gilead Sciences, Amgen e Celgene que são especializadas em biotecnologia.

Desse modo, serão consideradas nove empresas nesse estudo, a saber: Pfizer, Novartis, Roche, Merck\&Co, Sanofi, GlaxoSmithKline, AstraZeneca, Bristol-Myers Squibb e Eli Lilly

\section{MÉTOdo}

Com o objetivo de avaliar se as variáveis independentes impactam, ou não, na geração de valor da empresa ao longo do tempo, admite-se que a variável dependente EVA spread assume uma forma qualitativa expressando o impacto na geração de valor da empresa em duas categorias: positivo ou negativo. 
Foi utilizado o modelo de regressão logística binária que neste caso, assume-se que quando o EVA spread for positivo, a empresa criou valor, adotando-se igual a 1 e quando EVA spread for negativo, a empesa destruiu valor, adotando-se igual a 0

O modelo de regressão logística permite calcular a probabilidade de ocorrência de um evento estimado diretamente. No caso da variável dependente $\mathrm{Y}$ assumir apenas dois possíveis resultados (1 ou 0 ) e haver um conjunto de variáveis independentes $X 1, X 2, \ldots$, $\mathrm{X}$, o modelo de regressão logística é escrito conforme equação 1 :

onde,

$$
\left.P(\mathrm{Y}=1)=1 /\left(1+e^{(-g(x)}\right)\right)
$$

$$
g(x)=B_{0}+B_{1 X_{1}} \ldots+B_{p} X_{p}
$$

Os coeficientes B0, B1,... Bp são estimados a partir de um conjunto de dados, através do Método da Máxima Verossimilhança (MMV), com isso encontra-se uma combinação de coeficientes com o objetivo de maximizar a probabilidade da amostra ter sido observada. Para isso, considera-se certa combinação de coeficientes B0, B1,... , Bp e varia-se os valores de $X$. Observa-se que a curva logística tem um comportamento probabilístico no formato da letra $S$, que é uma característica da regressão logística. (Hosmer e Lemeshow ,1989).

A interpretação é dada da seguinte forma:

$\mathrm{P}$-valor $\leq \alpha$ : a associação é estatisticamente significativa.

P-valor $>\alpha$ : a associação não é estatisticamente significativa.

Complementar ao modelo, destaque-se que os dados estão dispostos em modelo de painel. Para análise dos dados será utilizado o programa estatístico Stata 12 com nível de significância adotado para os testes estatísticos de 0,05.

\section{ANÁlise dos RESUltados}

\subsection{Análise empírica}

Os dados demonstram que não existir nenhuma correlação forte (correlação $>0,8)$ não apresentando variável redundante. Dessa forma o modelo demonstra ausência de multicolinearidade ao não apresentar nenhuma variável redundante. 
Os dados da tabela 4 demonstram o número de ocorrências totais de empresas que destruíram ou adicionaram valor ao longo do período observado. Nota-se que o tamanho da amostra é $90 \mathrm{ob}-$ servações totalizando as 9 empresas analisadas pelo período de 10 anos. Observa-se ainda que no período total analisado houveram $64,4 \%$ de observação para adição de valor e 35,6\% de observação para destruição de valor.

Tabela 4 - Ocorrências totais de geração de valores anuais positivos e negativos

\begin{tabular}{ccc}
\hline EVA & Ocorrências & $\%$ \\
\hline 0 & 32 & 35,56 \\
1 & 58 & 64,44 \\
\hline Total & $\mathbf{9 0}$ & $\mathbf{1 0 0 , 0 0}$ \\
\hline
\end{tabular}

Fonte: Software Stata 12

Na tabela 5, pode-se observar a quantidade de período em que cada empresa adicionou ou destruiu valor onde podemos perceber que as empresas AstraZeneca, Bristol, Eli Lilly, GlaxoSmithKline e Roche foram as empresas que mais adicionaram valor e obtiveram pelo menos $70 \%$ do período com EVA spread positivo.

\section{Tabela 5 - Ocorrências de geração de valores anuais positivos e negativos por empresa}

\begin{tabular}{lrc}
\hline \multirow{2}{*}{ Empresas } & \multicolumn{2}{c}{ Dummy } \\
\cline { 2 - 3 } \multicolumn{1}{c}{ A } & $\mathbf{1}$ \\
\hline AstraZeneca & 3 & 7 \\
Bristol & 2 & 8 \\
Eli Lilly & 3 & 7 \\
GSK & 2 & 8 \\
Merk C.O & 6 & 4 \\
Novartis & 4 & 6 \\
PFIZER & 4 & 6 \\
Roche & 0 & 10 \\
Sanofi & 8 & 2 \\
\hline Total Geral & $\mathbf{3 2}$ & $\mathbf{5 8}$ \\
\hline
\end{tabular}

Fonte: Software Stata 12 
Na tabela 6, pode-se observar que o desvio padrão para todas as variáveis se demonstrou menor na análise within, que observa as variáveis independentes ao longo do tempo, do que na análise between, que observa as variáveis independentes entre os indivíduos. A análise reforça a utilização dos dados em painel,

Tabela 6-Análise de variância Between e Within

\begin{tabular}{|c|c|c|c|c|c|c|}
\hline Variável & Decomposição & Média & Desvio Padrão & Mínimo & Maximo & Observações \\
\hline \multirow{3}{*}{$\mathrm{y}$} & overall & 1.102 & 5.101 & -16.444 & 21.258 & $\mathrm{~N}=90$ \\
\hline & between & & 2.305 & -2.684 & 5.372 & $\mathrm{n}=9$ \\
\hline & within & & 4.610 & -16.958 & 20.744 & $\mathrm{~T}=10$ \\
\hline \multirow{3}{*}{$\mathrm{x} 1$} & overall & 7.270 & 2.380 & 3.566 & 14.570 & $\mathrm{~N}=90$ \\
\hline & between & & 2.312 & 4.684 & 10.634 & $\mathrm{n}=9$ \\
\hline & within & & 926 & 4.072 & 11.205 & $\mathrm{~T}=10$ \\
\hline \multirow{3}{*}{$\mathrm{x} 2$} & overall & 0 & 0 & 0 & 0 & $\mathrm{~N}=90$ \\
\hline & between & & 0 & 0 & 0 & $\mathrm{n}=9$ \\
\hline & within & & 0 & 0 & 0 & $\mathrm{~T}=10$ \\
\hline \multirow{3}{*}{$\mathrm{x} 3$} & overall & 1 & 0 & 0 & 1 & $\mathrm{~N}=90$ \\
\hline & between & & 0 & 0 & 1 & $\mathrm{n}=9$ \\
\hline & within & & 0 & 0 & 1 & $\mathrm{~T}=10$ \\
\hline \multirow{3}{*}{$\mathrm{x} 4$} & overall & 14.082 & 9.638 & 2.143 & 44.755 & $\mathrm{~N}=90$ \\
\hline & between & & 8.995 & 3.152 & 30.525 & $\mathrm{n}=9$ \\
\hline & within & & 4.491 & 2.647 & 28.312 & $\mathrm{~T}=10$ \\
\hline \multirow{3}{*}{$\mathrm{x} 5$} & overall & 69 & 32 & 32 & 156 & $\mathrm{~N}=90$ \\
\hline & between & & 31 & 40 & 125 & $\mathrm{n}=9$ \\
\hline & within & & 15 & 20 & 114 & $\mathrm{~T}=10$ \\
\hline \multirow{3}{*}{$\mathrm{x} 6$} & overall & 127 & 73 & 41 & 347 & $\mathrm{~N}=90$ \\
\hline & between & & 71 & 56 & 268 & $\mathrm{n}=9$ \\
\hline & within & & 28 & 33 & 206 & $\mathrm{~T}=10$ \\
\hline
\end{tabular}

Fonte: autores / Software Stata 12

A tabela 7 apresenta os resultados dos modelos de Painel Logit para os modelos de Efeito Fixo, que não leva em consideração a especificidade das empresas, Efeito Aleatório e População Média. Pode-se observar que com $5 \%$ de probabilidade de erro o modelo de Efeito Fisco se apresentou estatisticamente mais significante (prob chi $\left.^{2}<0,05\right)$, porém apresenta apenas uma variável com significância menor do que 0,05 e com percentual de acerto entre o predito e o observado de $36,67 \%$, considerando com cut-off de 0,5 .

O modelo de População média com $10 \%$ de probabilidade demonstrou ter duas variáveis com significância estatística relevante e com percentual de acerto entre o predito e o observado de $67,8 \%$, considerando com cut-off de 0,5. 
Dessa formal, o modelo PA se demonstrou mais bem ajustado e o EVA spread pode ser obtido pela equação 3:

$$
\begin{gathered}
\text { EVA Spread }=2,263-0,000063(\mathrm{x} 1)-25,215(\mathrm{x} 2)+4,945(\mathrm{x} 3) \\
+0,0000(\mathrm{x} 4)+0,017(\mathrm{x} 5)-0,001(\mathrm{x} 6)
\end{gathered}
$$

Os dados da tabela 7 demonstram inicialmente que as variáveis (x3) relação de faturamento inovadores sobre o faturamento total e (x5) quantidade de projeto em pipeline impactam positivamente no EVA spread, dado que coef é maior que zero, enquanto que as variáveis (x1) investimentos em PD\&I, (x2) relação de investimento em PD\&I sobre o faturamento total e $(x 6)$ investimento por projeto em pipeline impactam negativamente no EVA spread, dado que o coef é negativo. Nota-se que o volume de vendas de produtos Estabelecidos (x4) obteve coef igual a zero não demonstrando relevância no modelo. Cabe observar, que seu efeito pode estar refletido indiretamente no $\%$ de vendas de produtos inovadores sobre o total de vendas da empresa.

O impacto positivo das vendas de produtos inovadores, converge para os desafios competitivos apontados por Conti e Berndt (2014), Berndt e Dubios (2016) e Such (2000). Além disso, os resultados demonstram que a eficiência em PD\&I também impacta positivamente na geração de valor da empresa em consonância pela busca por maior produtividade em PD\&I demonstrada por Scannell (2011) e Pammolli (2020).

Dessa forma, é possível concluir que a presente pesquisa valida parcialmente as hipóteses inicialmente levantas de forma que, as venda de produtos inovadores e a eficiência em PD\&I, através do menor volume de investimento sobre o faturamento total, impactam positivamente na geração de valor ao acionista. No entanto, não foi possível validar a hipótese de que empresas que possuem mais intensidade de investimento em PD\&I adicionam valor conforme demonstrado por Chang, Xuemeng e Zhuojun (2018) e Ramos e Zilber (2018). 
Tabela 7 - Dados painel logist

\begin{tabular}{ccccc}
\hline Variável & indicador & PA & Efeitos Aleatórios & Efeitos Fixos \\
\hline \multirow{2}{*}{$\mathrm{x} 1$} & $\mathrm{coef}$ & $-6,30 \mathrm{E}-05$ & $-0,0001$ & $-0,0003$ \\
& $\mathrm{p}>\mathrm{z}$ & $(0,853)$ & $(0,893)$ & $(0,657)$ \\
\hline \multirow{2}{*}{$\mathrm{x} 2$} & $\mathrm{coef}$ & $-25,215$ & $-29,027$ & $-59,791$ \\
& $\mathrm{p}>\mathrm{z}$ & $(0,004)^{*}$ & $(0,025)^{*}$ & $(0,011)^{*}$ \\
\hline \multirow{2}{*}{$\mathrm{x} 3$} & $\mathrm{coef}$ & 4,945 & 5,715 & 0,366 \\
& $\mathrm{p}>\mathrm{z}$ & $(0,051)^{*}$ & $(0,051)^{*}$ & $(0,958)$ \\
\hline \multirow{2}{*}{$\mathrm{x} 4$} & $\mathrm{coef}$ & 0,000 & 0,000 & 0,000 \\
& $\mathrm{p}>\mathrm{z}$ & $(0,764)$ & $(0,777)$ & $(0,859)$ \\
\hline \multirow{2}{*}{$\mathrm{x} 5$} & $\mathrm{coef}$ & 0,017 & 0,019 & 0,0424 \\
& $\mathrm{p}>\mathrm{z}$ & $(0,498)$ & $(0,491)$ & $(0,267)$ \\
\hline \multirow{2}{*}{$\mathrm{x} 6$} & $\mathrm{coef}$ & $-0,001$ & $-0,003$ & 0,009 \\
& $\mathrm{p}>\mathrm{z}$ & $(0,920)$ & $(0,867)$ & $(0,638)$ \\
\hline \multirow{2}{*}{ Cons } & coef & 2,263 & 2,651 & \\
& $\mathrm{p}>\mathrm{z}$ & $(0,302)$ & $(0,389)$ & 90 \\
& $\mathrm{~N}$ & 90 & 90 & $-26,514$ \\
& Log Likelihood & & $-48,435$ & 21,05 \\
& Wald chi ${ }^{2}$ & 11,51 & 10,06 & 0,002 \\
& Prob $>$ chi $^{2}$ & 0,0738 & 0,122 & 36,67 \\
\hline
\end{tabular}

Fonte: Software Stata 12

Os dados da tabela 7 demonstram, ainda, o impacto estatisticamente significativo de cada variável observada. Os dados demonstram maior significância estatística nas variáveis de $(\mathrm{x} 2)$ relação de investimento em PD\&I sobre o faturamento total $(\mathrm{p}>\mathrm{z}=0,004<0,01)$ e (x3) relação de faturamento inovadores sobre o faturamento total $(\mathrm{p}>\mathrm{z}=0,051<0,1)$ na geração de valor da empresa validando as hipóteses de que empresas mais inovadoras e com maior eficiência em PD\&I agregam mais valor aos acionistas.

Buscando identificar um modelo estatisticamente ainda mais ajustado, foi proposto um modelo considerando apenas as variáveis (x2) de investimento em PD\&I sobre o faturamento, total, (x3) de faturamento de produtos inovadores sobre o faturamento total (x5) quantidade de projeto no pipeline. Os resultados são apresentados na tabela 8 . 
Tabela 8 - Dados painel logist modelo enxuto

\begin{tabular}{ccccc}
\hline Variável & indicador & PA & Efeitos Aleatórios & Efeitos Fixos \\
\hline \multirow{2}{*}{ x2 } & coef & $-25,239$ & $-29,175$ & $-58,74192$ \\
& $\mathrm{p}>\mathrm{z}$ & $(0,002)$ & $(0,024)$ & $(0,003)$ \\
\hline \multirow{2}{*}{$\mathrm{x} 3$} & $\mathrm{coef}$ & 4,964 & 5,639 & 1,434114 \\
& $\mathrm{p}>\mathrm{z}$ & $(0,025)$ & $(0,029)$ & $(0,695)$ \\
\hline \multirow{2}{*}{$\mathrm{x} 5$} & $\mathrm{coef}$ & 0,0188 & 0,0219 & 0,0264293 \\
& $\mathrm{p}>\mathrm{z}$ & $(0,075)$ & $(0,075)$ & $(0,233)$ \\
\hline \multirow{2}{*}{ cons } & coef & 1,680 & 1,989 & \\
& $\mathrm{p}>\mathrm{z}$ & $(0,205)$ & $(0,438)$ & \\
& $\mathrm{N}$ & & & $-26,683$ \\
& Log Likelihood & & $-48,605$ & 20,71 \\
& Wald chi ${ }^{2}$ & 11,45 & 10,44 & 0,0001 \\
& Prob $>$ chi $^{2}$ & 0,0095 & 0,015 & $1 \%$ \\
\hline
\end{tabular}

Fonte: Software Stata 12

Os resultados apresentados na tabela 8 demonstram que o modelo de População Média se apresentou estatisticamente significante (prob chi $\left.{ }^{2}<0,05\right)$, obtendo as três variáveis com significância estatística e o percentual de acerto entre o predito e o observado de $83 \%$, considerando com cut-off de 0,5. Dessa forma, o modelo PA com três variáveis observadas se demonstrou bem ajustado e o EVA spread pode ser obtido pela equação simplificada 4:

EVA Spread $=1,679-25,2387(x 2)+4,9641(x 3)+0,019(x 5)$

Os resultados demonstram que geração de valor da empresa é função do menor investimento em PD\&I sobre o faturamento total (x2), maior quantidade de projetos em pipeline (x5) e maior relação de faturamento de produtos inovadores sobre o faturamento total (x3), sendo consequentemente reflexo da eficiência em PD\&I, em consonância pela busca por maior produtividade em PD\&I demonstrada por Scannell (2011) e Pammolli (2020).

Assim, é possível inferir que o possível atraso no lançamento de novos produtos por parte dos executivos, por estarem priorizando os resultados de curto prazo, pode impactar negativamente na geração de valor da empresa conforme apontado por Salter (2012). No entanto, embora a significância do impacto na geração de valor 
das vendas de produtos estabelecidos tenha sido nula, o mesmo não deve ser negligenciado e tem um papel relevante dentro do cenário competitivo demostrado por Conti e Berndt (2014) Berndt e Dubios (2016) e Such (2000).

\subsection{Análise descritiva por categoria}

Das empresas analisadas nota-se que essa década foi de grande desafio econômico demonstrando um aumento significativo das empresas que destruíram valor, conforme gráfico 1. Observa-se que no início da década $67 \%$ das empresas adicionavam valor, ou seja, apresentaram EVA positivo. Esse número evoluiu significativamente até 2012, ano em que todas as empresas adicionaram valor. A partir de 2012, houve uma inversão nessa tendência e a quantidade de destruição de valor foi aumentando até que a partir de 2016 a maioria das empresas apresentaram destruição de valor.

No primeiro quinquênio da década analisada, entre o período de 2009 e 2013, haviam apenas 20\% de ocorrências em destruição valor. Enquanto que no segundo quinquênio, entre 2014 a 2018, a taxa aumentou para $51 \%$ de ocorrências em destruição de valor, com pode ser verificado no gráfico 2 .

Gráfico 1: Evolução anual da participação das empresas que adicionaram versus as que destruíram valor

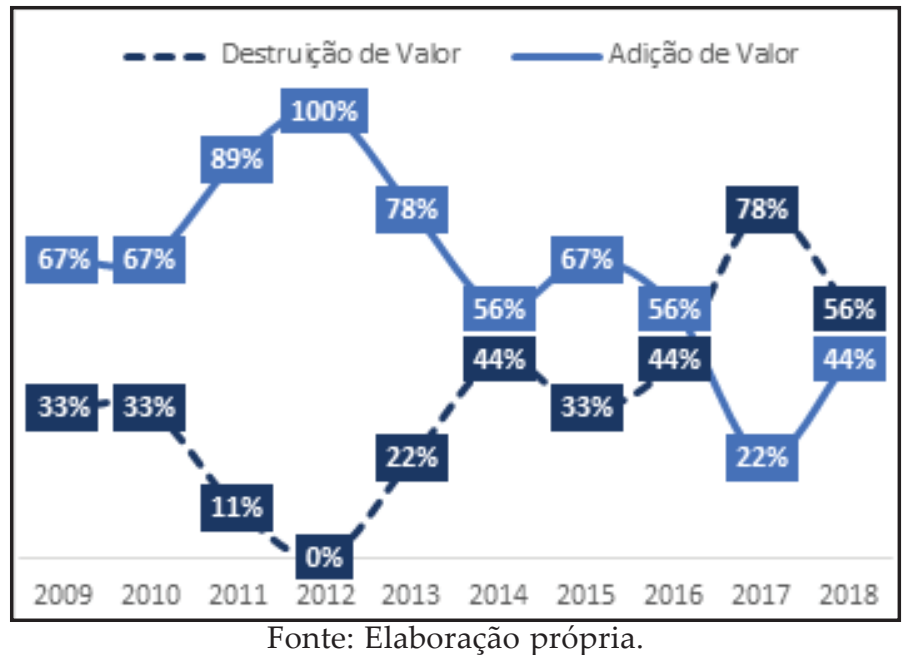


Gráfico 2: Comparativo da participação entre as empresas que adicionaram versus as que destruíram valor

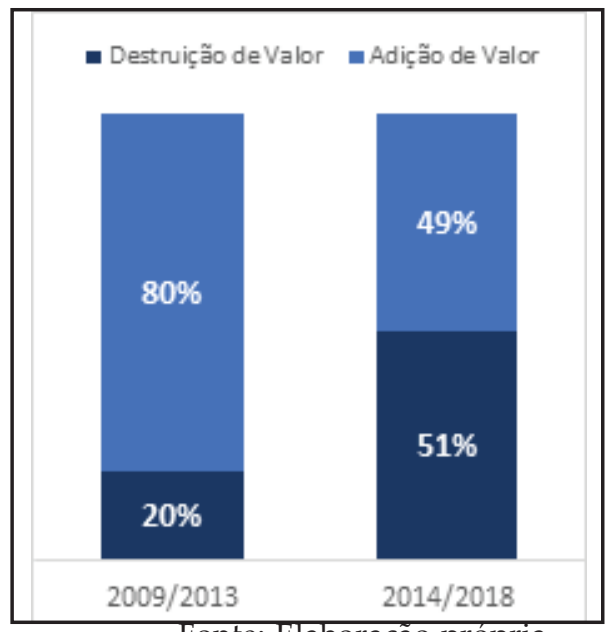

Fonte: Elaboração própria.

Essa tendência pode ser reflexo da escassez de novos medicamentos. Segundo o relatório Pharma (PHARMA, 2017) "uma grande queda no número de aprovações de medicamentos nos EUA no ano passado (...) serve para destacar a escassez de novos medicamentos".

As empresas que mais contribuíram para o aumento na taxa de destruição de valor no segundo quinquênio foram a AstraZeneca e Eli Lilly, que foram impactadas pela perda de patente de grandes marcas, a Novartis, que tem constantemente reportado em seus relatórios anuais o desafio de competir com genéricos e a Bristol, que investiu fortemente em PD\&I em 2015 ao adquirir a Flexus, empresa especializada em pesquisa e desenvolvimento de biotecnologia. Além disso, a Roche, Novartis e Sanofi também aumentaram o capital empregado ao investir em empresas de biotecnologia.

Nesse mesmo período, conforme apresentado na tabela 9, pode-se observar que o montante de vendas de produtos estabelecidos acumulados no período de 2014 a 2018 totalizaram US\$ 549,9 bilhões e recuaram 23,4\% sobre o período de 2009 a 2013. Enquanto isso, os produtos inovadores mantiveram-se estáveis, comparando os mesmos períodos. Consequentemente, é possível observar que a participação dos produtos inovadores no faturamento total atin- 
giu $50,5 \%$ do faturamento total com evolução de $9 \%$ entre os dois períodos observados.

A quantidade média de projetos por ano e por empresa reduziram 2,8\% quando comparamos o segundo quinquênio da década contra o primeiro. Enquanto isso, nesse mesmo período que os investimentos em PD\&I avançaram em 3,5\%. Quando comparado ao faturamento, observa-se um aumento na intensidade de investimento em PD\&I atingindo 19,4\% do faturamento. Assim, pode-se notar a escassez de lançamento de novos produtos combinado com o desafio de se manter competitivo no mercado de estabelecidos.

Tabela 9 - Evolução acumulada dos principais indicadores

\begin{tabular}{|l|r|r|r|}
\hline \multicolumn{1}{|c|}{ Indicadores } & $2009 / 2013$ & $2014 / 2018$ & variação \\
\hline Faturamento produtos estabelecidos (US\$ bilhões) & 717,5 & 549,9 & $-23,4 \%$ \\
Faturamento produtos inovadores (US\$ bilhões) & 868,3 & 868,3 & $0,0 \%$ \\
Faturamento Inovadores sobre total (\%) & $46,4 \%$ & $50,5 \%$ & $9,0 \%$ \\
Despesas com PD\&I (US\$ bilhões) & 321,4 & 332,8 & $3,5 \%$ \\
PD\&I sobre faturamento (\%) & $17,2 \%$ & $19,4 \%$ & $12,8 \%$ \\
Projetos no pipeline (quantidade média anual) & 631,8 & 614,4 & $-2,8 \%$ \\
Investimento médio anual por projeto em pipeline & 101,7 & 108,3 & $6,5 \%$ \\
\hline
\end{tabular}

Fonte: Elaboração própria.

\subsection{Análise descritiva por categoria - investimentos em P\&DI}

Conforme gráfico 3, as empresas que destruíram valor investiram em média anualmente US\$179 milhões em PD\&I por projeto nessa década, enquanto que as empresas adicionaram valor investiram em média US\$ 73 milhões em PD\&I por projeto, o que representa uma taxa de investimento anual médio per capta de aproximadamente $60 \%$ menor.

A taxa de investimento por projeto tem se demonstrado estável ao longo do período analisado. Conforme gráfico 4, é possível observar que a diferença na taxa de investimento por projeto entre os dois grupos de empresas tem sido constante e se demonstrou estável nos últimos 10 anos com pequenas alterações entre o primeiro e segundo quinquênio.

Dessa forma, as empresas que possuem maior probabilidade de adição de valor apresentaram maior eficiência nos investimentos 
em projetos inovadores corroborando para busca por maior produtividade em PD\&I demonstrada por Scannell (2011).

Gráfico 3: Investimento médio anual por projeto no pipeline (US\$ milhões/projeto)

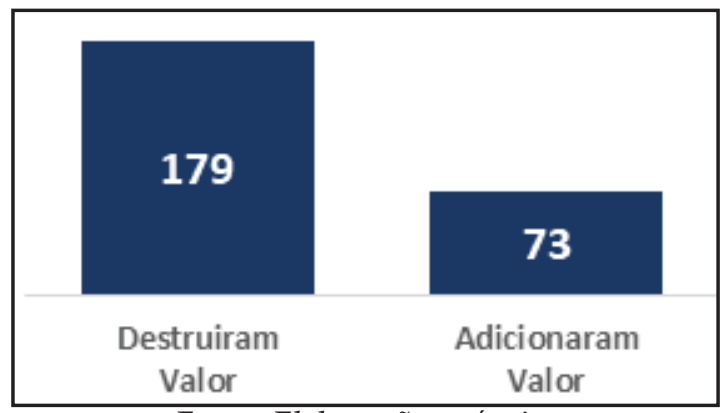

Fonte: Elaboração própria.

Gráfico 4: Investimento médio anual por projeto no pipeline por empresa (US\$ milhões/projeto)

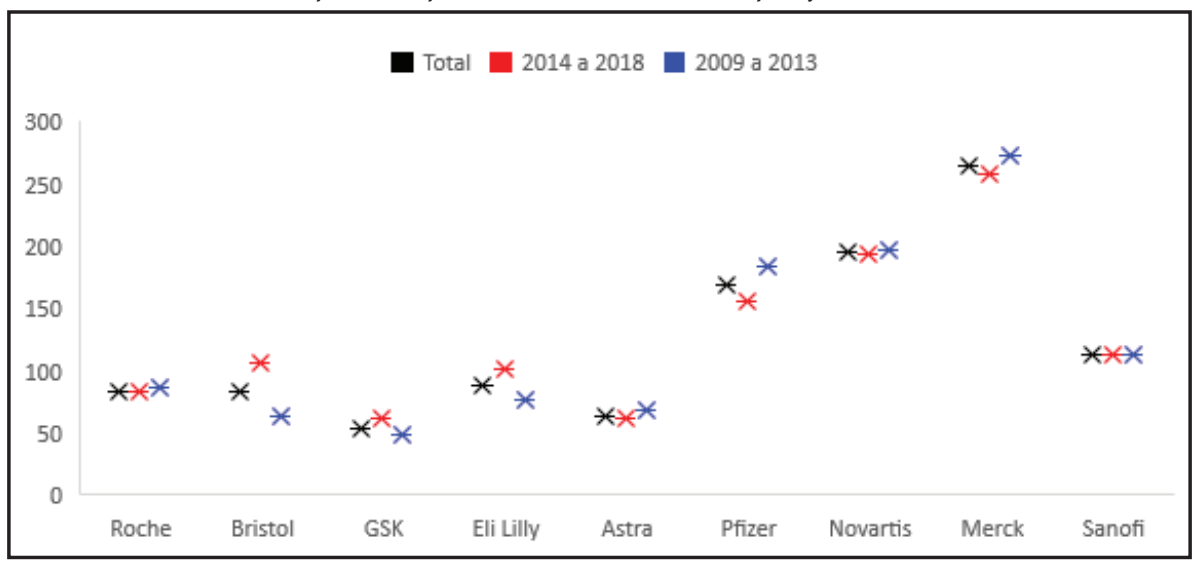

Fonte: Elaboração própria.

O menor investimento em P\&DI por projeto pode ser explicado pela maior quantidade de projetos em pipeline impulsionado pelo menor montante de investimentos, conforme gráfico 5 .

O montante médio anual de investimentos em PD\&I das empresas que destruíram valor foi de US $\$ 33,9$ bilhões enquanto que o montante médio anual de investimentos das empresas que 
adicionaram valor foi de US\$ 31,6 bilhões, o que representa um montante $7 \%$ menor de investimentos em PD\&I para as empresas que adicionaram valor.

Em termos que quantidade de projetos, as empresas que destruíram valor tiveram em média 189 projetos em pipeline por ano enquanto que as empresas que adicionaram valor tiveram em média 434 projetos por ano, resultando em uma superação de $130 \%$.

Gráfico 5: Montante de investimentos médio anual em PDEI (US\$ bilhões) e quantidade média anual de projetos no pipeline

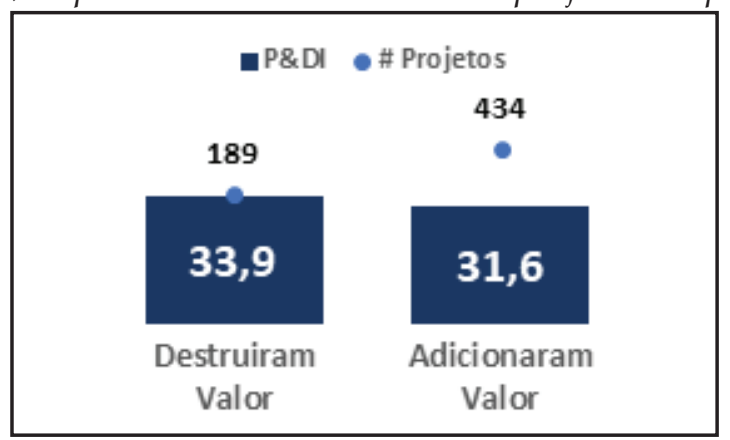

Fonte: Elaboração própria.

Por outro lado, o gráfico 6 apresenta as empresas que destruíram valor investiram 16,9\% do faturamento em PD\&I, enquanto que as empresas adicionaram valor investiram em média 19,9\% do faturamento em PD\&I, o que representa uma intensidade 17,5\% maior de investimento em PD\&I.

Conforme gráfico 7, podemos observar que entre os anos de 2009 e 2013 as empresas que possuem maior probabilidade de adição de valor investiram 18,3\% do faturamento total em PD\&I enquanto que as empresas que destruíram valor investiram $16,3 \%$, o que resultou em uma diferença de intensidade de investimento em 2,1 p.p.

Quando observamos entre os anos de 2014 e 2018 nota-se que apesar de ambas as empresas intensificaram os investimentos em PD\&I relativos ao faturamento, as empresas que adicionaram valor aceleraram mais as taxas de investimentos em PD\&I e atingiram $21,5 \%$ do faturamento total enquanto que as empresas que destruíram valor investiram 17,7\% do faturamento total em PD\&I, ampliando a diferença entre elas para 3,8 p.p. 
Gráfico 6: Investimento em PDEI sobre faturamento (\%)

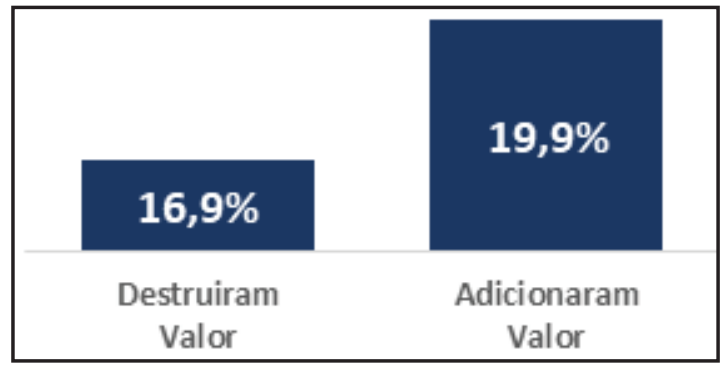

Fonte: Elaboração própria.

Gráfico 7: Investimento em PDEI sobre faturamento (\%) por período

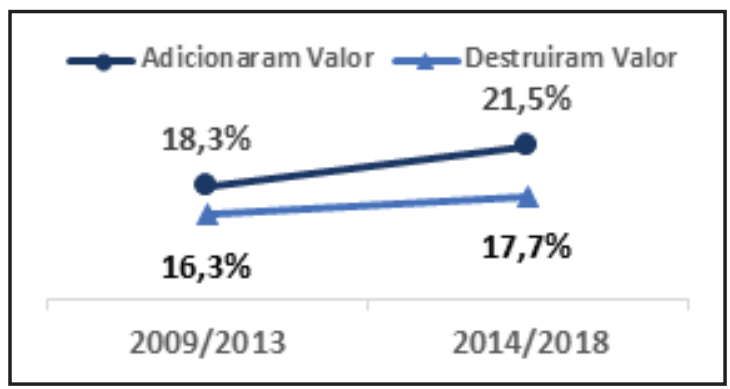

Fonte: Elaboração própria.

Apesar de ambas as empresas terem evoluído na taxa de investimento em PD\&I sobre o faturamento total, os gráficos 8 e 9 demonstram que o cenário entre os grupos foi bem distinto. As empresas com maior probabilidade de adição de valor obtiveram um crescimento médio anual de $2,9 \%$ em investimento em PD\&I e de 2,6\% em vendas entre os anos de 2014 e 2018. Enquanto isso, as empresas que destruíram valor apresentaram um crescimento médio anual de 1,7\% em investimento em PD\&I e uma involução $0,4 \%$ no faturamento. 
Gráfico 8: CAGR de investimento em PDEI e faturamento total para empresas que adicionaram valor

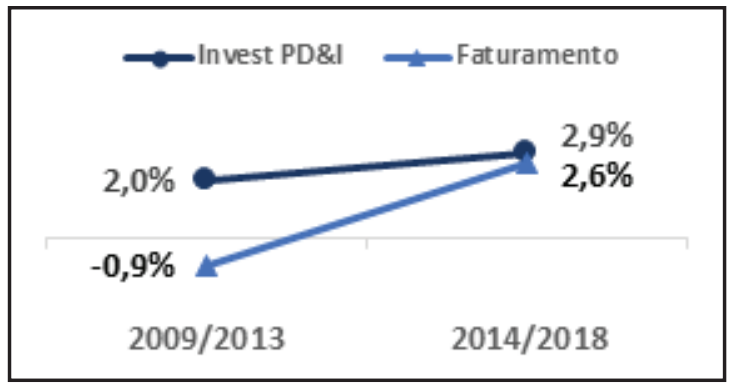

Fonte: Elaboração própria.

Gráfico 9: CAGR de investimento em PDEI e faturamento total para empresas que destruíram valor

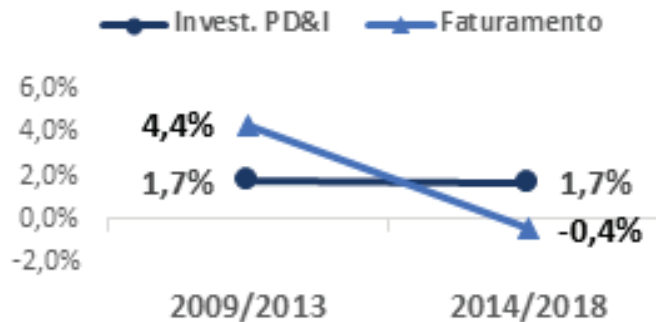

Fonte: Elaboração própria.

Dessa forma foi possível buscar evidencias de que as empresas com mais intensidade em investimento em PD\&I adicionam valor conforme afirmado por de Chang, Xuemeng, Zhuojun (2018) e Ramos e Zilber (2015). Porém, o aumento da intensidade de investimento em PD\&I deve ser refletido em aumento de vendas, o que sugere novamente que o possível atraso no lançamento de novos produtos por parte dos executivos, por estarem priorizando os resultados de curto prazo, pode impactar negativamente na geração de valor da empresa conforme apontado por Salter (2012).

\subsection{Análise descritiva por categoria - faturmento}

As empresas que destruíram valor são menos inovadoras, conforme possível observar no gráfico 10. As empresas que destruíram 
valor obtiveram $44 \%$ do seu faturamento médio anual, excluindo outros negócios, oriundos de produtos inovadores enquanto que as empresas que adicionaram valor possuíram 54\% do seu faturamento médio anual.

Gráfico 10: Participação média anual das vendas dos produtos inovadores nas vendas totais.

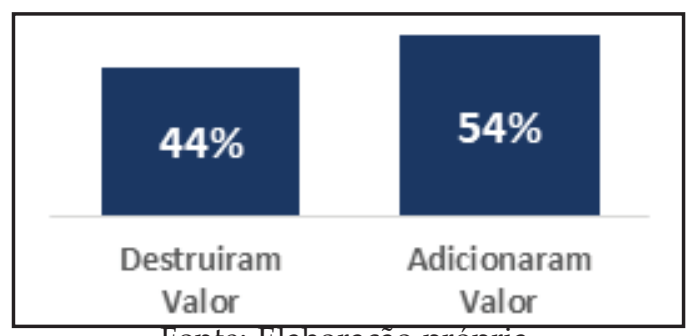

Fonte: Elaboração própria.

Além disso, as empresas que adicionaram valor foram mais eficientes na gestão dos produtos estabelecidos, conforme gráfico 11. A taxa média de crescimento de vendas anuais entre 2009 e 2013 foi de $1,5 \%$ para as empresas que adicionaram valor e $7,9 \%$ para as empresas que destruíram valor. Para o período de 2014 a 2018, as empresas que adicionaram valor apresentaram um crescimento médio anual de 1,3\% nos produtos estabelecidos, enquanto que as empresas que destruíram valor, obtiveram uma involução de $4,6 \%$.

Gráfico 11: Taxa de crescimento anual composto das vendas dos produtos estabelecidos

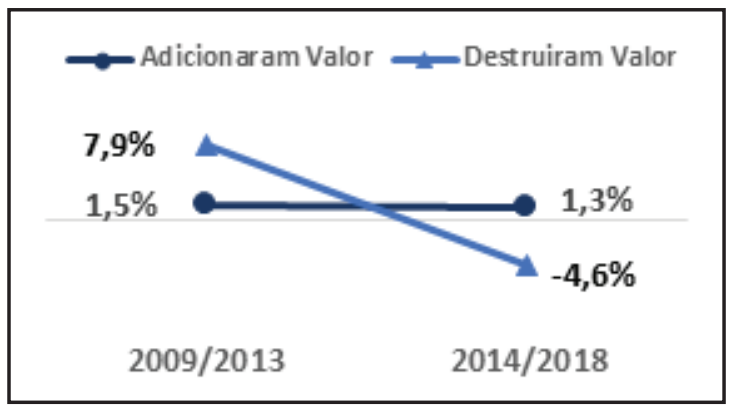

Fonte: Elaboração própria. 
Novamente é possível concluir que as empresas com maior probabilidade da geração de valor da empresa mantiveram maior velocidade de lançamento de novos produtos e fizeram relativamente melhor gestão dos produtos estabelecidos criaram diferencial competitivo e convergindo para os desafios competitivos (Conti e Berndt, 2014; Berndt e Dubios, 2016; Such, 2000). Dessa forma, foi possível validar as hipóteses levantadas de que as empresas que mais lançam produtos inovadores e/ou que melhor gerenciam os produtos estabelecidos no mercado competitivo adicionam mais valor.

Portanto a pesquisa contribui para o entendimento de que adequado nível de investimentos em PD\&I no setor farmacêutico por protejo constante no pipeline e a maior celeridade no lançamento de novos produtos, de acordo com o recorte amostral analisado, impactam positivamente na geração de valor da empresa.

\section{CONCLUSÃo}

Consoante ao objetivo geral da pesquisa, as evidências empíricas desse estudo demonstram um impacto positivo na geração de valor decorrente do processo de investimentos em pesquisa desenvolvimento e inovação. Os resultados demonstram que a eficiência no processo de PD\&I resultante da maior quantidade de projeto em pipeline, menor relação de investimento sobre faturamento e maior relação de faturamento de produtos inovadores impactam positivamente na geração de valor da empresa.

Adicionalmente, foi realizada uma análise descritiva dos dados e observou que a década foi bem desafiadora para as empresas analisadas. A análise demonstrou uma grande involução da quantidade de empresas que adicionaram valor reduzindo de $82 \%$ no primeiro quinquênio para $48 \%$ no segundo quinquênio como reflexo das perdas de patentes, competição com genéricos, atos investimentos em PD\&I e em ativos imobilizados decorrente dos movimentos de aquisição de empresas especializadas em biotecnologia.

Como análise complementar, o estudo foi categorizando dois grupos de empresas dividindo em empresas que adicionaram valor e empresas que destruíram valor. Para a categoria das empresas que adicionaram valor foi considerada as empresas que obtiveram 
EVA spread positivo em sete dos 10 anos observados, ou seja $70 \%$ do período analisado.

A análise demonstra que as empresas que adicionaram valor foram mais eficientes na produtividade de PD\&I com investimento menor em $60 \%$ por projeto no pipeline do que as empresas que destruíram valor, mantiveram taxas de crescimento em PD\&I mais alinhadas ao crescimento do faturamento, foram mais inovadores obtendo $54 \%$ do faturamento oriundos de produtos inovadores contra $44 \%$ das empresas que destruíram valor e fizeram melhor gestão dos produtos estabelecidos com taxas de crescimento de 1,3\% no segundo quinquênio contra uma involução de $4,6 \%$ obtivo pelas empresas que destruíram valor.

Foi identificado também na análise de resultados que as empresas que aceleram os lançamentos de novos produtos e procuram ser mais eficientes em PD\&I demonstram maior probabilidade de geração de valor o que é vital para que a empresa possa enfrentar os desafios competitivos (CONTI E BERNDT, 2014; BERNDT; DUBIOS, 2016; ROCHA; SANTOS; VIEIRA, 2016; SUCH, 2000).

O processo de desenvolvimento de novos produtos é complexo e tem se apresentado bem desafiador nos últimos anos com longos períodos de desenvolvimento (PHARMA, 2012) e redução das taxas de sucesso de desenvolvimento (2010). Embora, os motivos do insucesso dos projetos estejam em sua maioria relacionados às questões técnicas, existem diversos fatores que impactam no desenvolvimento de um novo produto como questões econômicas, expetativa de retorno de investimentos e problemas de gestão (DIMASI 2001; BUONANSEGNA, MAIER, LI-YING 2014).

Esse estudo demonstra adicionalmente a importância da minimização do impacto do conflito de agência na geração de valor da empresa, apresentando indícios de que a responsabilidade dos gestores na condução dos projetos no pipeline é significativa para a geração de valor, pois a hipótese central foi validada.

Dessa forma, os resultados desse estudo sugerem que os retardo do lançamento de novos produtos deve ser evitado e que os investimentos em PD\&I não podem ser são postergados pela necessidade de gestão de curto prazo (SALTER 2012). 
Diversos mecanismos como a implementação de transparência financeira (MESSIER, 2012), a adequada implementação do sistema de remuneração (MERCHANT; STEDE, 2012), a adequada estrutura de governança (SHAIKH; PETERS, 2018) podem ser utilizados para evitar que os projetos sejam postergados e auxiliam na convergência do comportamento dos executivos para a expectativa dos acionistas.

\section{REFERÊNCIAS}

AGUIAR, A. B. et al. Análise Dos Direcionadores De Valor Em Empresas Brasileiras. Revista de Administração Mackenzie, v. 12, n. 2, p. 90-112, 2011.

ALMEIDA, L. et al . Comparative analysis between EVA® and traditional financial (accounting) indicators in Brazilian civil construction companies: a documentary study. Gest. Prod., São Carlos, v. 23, n. 4, p. 733-756, Dec. 2016.

ARTRIL, P., Myopic Management, dez. 2015. Disponível em: <http://www.accaglobal.com/ gb/en/student;exam-support-resources $>$. Acesso em: 20 fev. 2018

AUSTIN, L., "Benchmarking to economic value added: The case of Airways Corporation of New Zealand Limited", Benchmarking: An International Journal, Vol. 12 No. 2, pp. 138-150, 2005

BATISTA, A. Regressão Logística, uma introdução ao modelo estatístico exemplo de aplicação ao Revolving Credit - 1st ed, Vida Econômica Editorial, 2015, p. 26.

BERNDT, E. R.; DUBOIS, P. Impacts of Patent Expiry on Daily Cost of Pharmaceutical Treatments in Eight OECD Countries, 2004-2010. International Journal of the Economics of Business, [s. 1.], v. 23, n. 2, p. 125-147, 2016.

BLOCK, J. H. R\&D investments in family and founder firms: An agency perspective. Journal of Business Venturing, [s. 1.], v. 27, n. 2, p. 248-265, 2012.

BREALEY, R; MYERS, S; ALLEN, F.. Principles of Corporate Finance - 12th ed, McGraw-Hill Irwin, 2016, p. 9-13.

BREWER, P. C.; CHANDRA, G. Economic Value Added (EVA): Its Uses and Limitations. SAM Advanced Management Journal (07497075), [s. 1.], v. 64, n. 2, p. 4, 1999

B TG, P. Ebitda: o que é, para que serve e como calcular? 2019. Disponível em: < $<$ htps:// www.btgpactualdigital.com/blog/financas/ebitda-o-que-e-para-que-serve-e-como-calcular $>$. Acesso em: 11 abr. 2020

BUONANSEGNA, E., SALOMO, S., MAIER, A. M., LI-YING, J. Pharmaceutical new product development: why do clinical trials fail?. R\&D Management, 44(2), p. 189-202, 2014.

CAMERON, A. TRIVEDI, P. Microeconometrics: methods and applications. Cambridge university press, 2005

CHANG, L.; XUEMENG, G.; ZHUOJUN, W. R\&D Expenses and Operating Performance in Pharmaceutical Industry. 2018 International Conference on Humanities Education and Social Sciences (ICHESS 2018), p. 525-530, 2018. 
CONTI, R.; BERNDT, E. Specialty drug prices and utilization after loss of U.S. patent exclusivity, 2001-2007. National Bureau of Economic Research, 2014.

CRESWELL, J.W. Projeto de Pesquisa: Métodos Qualitativos, Quantitativo e Misto. Porto Alegre: Editora Artmed, 2007.

CUNHA, M.; MARTINS, E.; ASSAF NETO, A.. Avaliação de empresas no Brasil pelo fluxo de caixa descontado: evidências empíricas sob o ponto de vista dos direcionadores de valor nas ofertas públicas de aquisição de ações. Rev. Adm. (São Paulo), São Paulo, v. 49, n. 2, p. 251-266, 2014.

CVM: Instrução CVM № 527, de 04 de outubro de 2012. 2012. Disponível em: <http://www. cvm.gov.br/legislacao/instrucoes/inst527.html>. Acesso em: 11 abr. 2020

DELOITTE. Measuring the Return from Pharmaceutical Innovation 2018. Unlocking R\&D Productivity. Disponível em $<$ :https://www2.deloitte.com/uk/en/pages/life-sciences-and-healthcare/ articles/measuring-return-from-pharmaceutical-innovation.html> Acesso em 03 abril 2019.

DIMASI, J. A. Risks in new drug development: approval success rates for investigational drugs. Clinical Pharmacology \& Therapeutics, 69(5), p. 297-307, 2001

DIMASI, J. A., FELDMAN, L., SECKLER, A., \& WILSON, A. Trends in risks associated with new drug development: success rates for investigational drugs. Clinical Pharmacology \& Therapeutics, 87(3), p. 272-277, 2010.

DIMASI, J., GRABOWSKI, H., \& HANSEN, R. (2016). Innovation in the pharmaceutical industry: new estimates of R\&D costs. Journal of health economics, 47, p. 20-33, 2016.

FEYZRAKHMANOVA, M; GURDGIEV, C. Patents and R\&D expenditure effects on equity returns in pharmaceutical industry. APPLIED ECONOMICS LETTERS,.Dublin, v. 23, p. 278-283, 2016.

FERGUSON, R.; RENTZLER, J.; YU, S. Does Economic Value Added (EVA) Improve Stock Performance Profitability? Journal of Applied Finance, [s. 1.], v. 15, n. 2, p. 101-113, 2005

FLEMING, G.; HEANEY, R.; MCCOSKER, R. Agency costs and ownership structure in Australia. Pacific-Basin Finance Journal, [s. 1.], v. 13, n. 1, p. 29-52, 2005.

GUIA INTERFARMA 2019. Disponível em: < https://www.interfarma.org.br/guia/guia-2019/> Acesso em: 09 novembro 2019.

GUjARATI, D., PORTER, D. Econometria Básica, Amgh Editora - 5th ed, Amgh Editora, 2011, p. 9-13.

GUERMAT, C.; MISIRLIOGLU, I. U.; AL-OMUSH, A. M. The long-term effect of economic value added adoption on the firm's business decision. Accounting Research Journal, [s. 1.], v. 32, n. 3, p. 496-513, 2019.

GRAHAM, F., Humphreys, I. and Austin, L., "Benchmarking to economic value added: The case of Airways Corporation of New Zealand Limited", Benchmarking: An International Journal, Vol. 12 No. 2, pp. 138-150, 2005

HENRY, G. GRABOWSKI; WANG, R. The Quantity And Quality Of Worldwide New Drug Introductions, 1982-2003. Heath Tracking, março/abril, p. 452-460, 2006. 
HOANG, L.; TUAN, T; NHA, P. LONG, T.; PHOUNG, T. Impact of Agency Costs on Firm Performance Evidence from Vietnam. Organizational and Markets in Emerging Economies. 2019, vol 10, p. 294-309

HOSMER, D. \& LEMESHOW, S. Applied Logistic Regression. Wiley series in probability and mathematical statistics. New York. Jonh Wiley \& Sons. 1989.

INDUSTRIAL R\&D--Life Science. R\&D Magazine, [s. 1.], v. 53, n. 7, p. 46-47, 2011.

JANSEN, C.; MECKILNG. Theory of the firm: Managerial Behaviour, Agency Costs and Ownership Structure Journal of Financial Economics. New York, 1976, p. 305-360

KIM, J.-B.; LI, Y.; ZHANG, L. CFOs versus CEOs: Equity incentives and crashes. Journal of Financial Economics, [s. 1.], v. 101, n. 3, p. 713-730, 2011

KOR, Y. Y. Direct and interaction effects of top management team and board compositions on R\&D investment strategy. Strategic Management Journal (John Wiley \& Sons, Inc.), [s. 1.], v. 27, n. 11, p. 1081-1099, 2006.

MADURA, J. International Financial Management, 13th ed., Cengage Learning, 2016, p. 3-4

MAUBOUSSIN, M. J. What Does an EV/EBITDA Multiple Mean? 2018. Disponível em: $<$ https://www.bluemountaincapital.com/wp-content/uploads/2015/03/What-Does-an-EV-EBITDA-Multiple-Mean.pdf $>$. Acesso em: 11 abr. 2020

MAUBOUSSIN, M. J.; CALLAHAN, D. Capital Allocation: Evidence, Analytical Methods, and Assessment Guidance. Journal of Applied Corporate Finance, [s. 1.], v. 26, n. 4, p. 48-74, 2014.

MCKELLAR, M. R. et al. The Value of Patent Expiration. Forum for Health Economics \& Policy, [s. 1.], v. 15, n. 2, p. 1, 2012.

MCKNIGHT, P. J.; WEIR, C. Agency costs, corporate governance mechanisms and ownership structure in large UK publicly quoted companies: A panel data analysis. Quarterly Review of Economics \& Finance, [s. 1.], v. 49, n. 2, p. 139-158, 2009.

MERCER, Z. C. EBITDA Single-Period Income Capitalization for Business Valuation. Business Valuation Review, 35(3), 86-102, 2016

MERCHANT, K. A \& VAN DER STEDE, W. A. Management control systems. 3rd ed. Prentice Hall, 2012.

MESSIER, F.; GLOVER, Steven M.; Prawitt, Douglas F. Auditing \& Assurance Services - A systematic approach. 8th edition, New York: McGraw-Hill/Irwin, 2012, p.6

MISTRY, D., SINGH, S., \& SINGH, S. A Study of Shareholder's Value and Financial Variablesof Indian Pharma Industry: An Empirical Analysis'. Gurukul Business Review, 3, 56-63, 2013

PAMMOLLI, F., MAGAZZINI, L., \& RICCABONI, M. The productivity crisis in pharmaceutical R\&D. Nature reviews Drug discovery, 10(6), 428-438, 2011.

PAMmOlli, F., RighetTO, L., ABRIGNANI, S., PANI, L., PELICCI, P. G., \& RABOSIO, E. The endless frontier? The recent increase of R\&D productivity in pharmaceuticals. Journal of translational medicine, 18, 1-14, 2020. 
PEREZ, M. Métricas de retorno e a geração de valor ao acionista. UNISANTA Law and Social Science - p. 189 - 202; Vol. 4, no 2, 2015.

PHARMA, E. Evaluate Pharma World Preview 2013 Outlook to 2018. (2013). Disponível em: $<$ https://info.evaluategroup.com/rs/evaluatepharmaltd/images/EvaluatePharma World Preview 2013 Outlook to 2018.pdf >. Acesso em: 09 novembro 2019

PHARMA, E. Evaluate Pharma World Preview 2014 Outlook to 2020. (2014). Disponível em: $<$ https://info.evaluategroup.com/rs/evaluatepharmaltd/images/eP240614.pdf $>$. Acesso em: 18 fevereiro 2020

PHARMA, E. Evaluate Pharma World Preview 2016 Outlook to 2022. (2016). Disponível em: $<$ https://info.evaluategroup.com/rs/607-YGS-364/images/wp16.pdff $>$. Acesso em: 18 fevereiro 2020

PHARMA, E. Evaluate Pharma World Preview 2017 Outlook to 2022. (2017). Disponível em: $<$ https://info.evaluategroup.com/rs/607-YGS-364/images/WP17.pdf $>$. Acesso em: 09 novembro 2019

PHARMA, E. Evaluate Pharma World Preview 2018 Outlook to 2024. (2018). Disponível em: $<$ https://info.evaluategroup.com/WP2018-CS.html>. Acesso em: 09 novembro 2019

PHARMA, E. Evaluate Pharma World Preview 2019 Outlook to 2024. (2019). Disponível em: $<$ https://info.evaluate.com/rs/607-YGS-364/images/EvaluatePharma World Preview 2019. pdf $>$. Acesso em: 09 novembro 2019

PHRMA, R. Medicines in Development for COPD 2012 Report, Disponível em: $<\underline{\text { https:// }}$ www.phrma.org/Report/Medicines-in-Development-for-COPD-2012-Report1> Acesso em: 23 abril 2020

PINTO, J. E.; ROBINSON, T. R.; STOWE, J. D. Equity valuation: A survey of professional practice. Review of Financial Economics, [s. 1.], v. 37, n. 2, p. 219-233, 2019

QI, B. et al. Does internal control over financial reporting really alleviate agency conflicts? Accounting \& Finance, dez. 2017. v. 57, n. 4, p. 1101-1125.

RAMOS, A; ZILBER, S. Efeitos da inovação no desempenho das firmas brasileiras: Rentabilidade, Lucro, Geração de Valor ou Percepção do Mercado? Revista de Administração da UNIMEP. v.14, n.3, p.165-193, 2016.

ROCHA, A. F. R.; SANTOS, I. C. D.; VIEIRA, A. M. Semi-open Innovation: an Approach to the Innovation Typology. Future Studies Research Journal, v. 10, n. 1, p. 55-81, 2018.

SANTOS,J.; GÓIS, A.; REBOUÇAS, S.; FILHO, J. O Impacto do Investimento na Capacidade Inovadora da Empresa. Revista de Administração e Inovação, São Paulo, v.12, n.1, p.303325, jan./mar. 2015

SALTER, S., How Short-Termism Invites Corruption...And What to Do About it. April, 2012. Harvard Business School Research Paper No. 12-094.

SCANNELL, J. et al. Global Pharma: R\&D Productivity Follows Moore's Law Backwards; Does Anyone Know Why? Bernstein Black Book - The Long View: Pan-European Perspectives (2011 Edition), [s. 1.], p. 89-95, 2011. 
SEN, P. K. E SINGER, J. M. Large Sample Methods in Statistics: An Introduciton with Applications. Chapman and Hall, London, 1993.

SHAIKH, I. A.; PETERS, L. The value of board monitoring in promoting R\&D: a test of agency-theory in the US context. Journal of Management \& Governance, [s. 1.], v. 22, n. 2, p. 339-363, 2018

SHARMA, A K., KUMAR, S.. “Economic value added (EVA)-literature review and relevant issues." International journal of economics and finance 2.2 (2010): 200-220.

SILVA, G. L. Modelos Logísticos para Dados Binários. Dissertação de Mestrado, IME-USP, 1992.

SILVA, R.; SEIBERT, R. Governança Corporativa - História e Tendências. Revista Interdisciplinar Científica Aplicada, Blumenau, v.9, n.3, p.76-101, TRIII 2015. ISSN 1980-7031.

STEWART, B. EVA, not EBITDA: A New Financial Paradigm for Private Equity Firms. Journal of Applied Corporate Finance, [s. 1.], v. 31, n. 3, p. 103-115, 2019. DOI 10.1111/jacf.12365.

STUMPP, P. M., et al. "Putting EBITDA in perspective: ten critical failings of EBITDA as the principal determinant of cash flow." Published in Moody's Investor Service Global Credit Research (2000).

$\mathrm{SUCH}, \mathrm{D} \mathrm{C}$ et al. Effect of multiple-source entry on price competition after patent expiration in the pharmaceutical industry. Health services research, vol. 35, n2 , p. 529-47, 2000.

TRIPATHI, V. Agency Theory, Ownership Structure and Capital Structure: An Empirical Investigation in the Indian Automobile Industry. Asia-Pacific Management Accounting Journal, India, 2019, Volume 14

VANDOROS, S.; KANAVOS, P. The generics paradox revisited: empirical evidence from regulated markets. Applied Economics, [s. 1.], v. 45, n. 22, p. 3230-3239, 2013.

WIRAWAN, D. I. Effects of EVA (economic value added), EVA spread, EVA momentum and return on assets on stock return: empirical study in Indonesian stock market (Doctoral dissertation, Master Thesis, Gadjah Mada University, Indonesia), 2011

WONG, C. H., SIAH, K. W., \& LO, A. W. Estimation of clinical trial success rates and related parameters. Biostatistics, 20(2), p. 273-286, 2019.

Recebido em: 7-10-2021

Aprovado em: 2-12-2021

Avaliado pelo sistema double blind review.

Disponível em http://mjs.metodista.br/index.php/roc 